\title{
Internal Political and International Aspects of Regulation of the Shadow Sector as a Threat to Economic Security
}

\author{
Olga A. Stepicheva ${ }^{1} \&$ Vladislav M. Yuryev ${ }^{2}$ \\ ${ }^{1}$ Medical Institution, Tambov State University named after G. R. Derzhavin, Tambov, Russia \\ ${ }^{2}$ Tambov State University named after G. R. Derzhavin, Tambov, Russia \\ Correspondence: Olga A. Stepicheva, Medical Institution, Tambov State University named after G. R. Derzhavin, \\ Tambov, Russia. 5-122, Komsomolskaya square, Tambov, Russia. Tel: 7-475-272-3555. E-mail: \\ st_olga@mail.ru
}

Received: July 30, 2014 Accepted: August 30, 2014 Online Published: November 14, 2014

doi:10.5539/ass.v10n23p9

URL: http://dx.doi.org/10.5539/ass.v10n23p9

\begin{abstract}
The purpose of this research is to develop methodologies for the development of regulatory mechanisms of the shadow economy in Russia from the viewpoint of the theory of economic interests. To implement the set goals have been resolved following scientific problems:

- Analysis of mechanisms of regulation of shadow economic relations in the Russian Federation.

- To develop methodological basis of the theory of economic interests in the informal sector of the Russian Federation and to formulate practical recommendations for their effective implementation.

- To analyze the patterns of development of economic relations in the informal sectors of the Russian Federation.

- Identify actions the improvement of the tools of regulation of economic policy in the informal sectors of the Russian Federation.

- Develop a methodology to neutralize shadow relations as the basis for the correction of imbalances economic interests in Russia.

Theoretic-methodological basis of the study was the theory of economic interests, which is a research program founded on the principles of relativism, scientific attractiveness as research methodology problems of influence of shadow economic relations at the national economic security is the ability of dialectical synthesis, which no methodology of "individualism", neither the methodology of "holism".

The study found that shadow the potential of the Russian society because of its high social structure that has allowed to define major directions of social-economic policy in order to neutralize the effects of the shadow economic activity.

Received confirmation of the fact that in Russia there are two groups of subjects of the shadow economy, guided by their own interests: the first group is driven by the desire for personal enrichment, the second forced to withdraw "in the shadow" to survive in the conditions of unreasoned economic (tax) policy and administrative arbitrariness.

It is proved that the constructive component of the shadow economy is concentrated mainly on the production stage of the process of reproduction, and its destructive part - in the sphere of exchange and distribution.

Based on the theory of economic interests has developed instruments for the protection of national-state economic interests in Russia in the context of combating dangerous manifestations of the shadow economy.
\end{abstract}

Keywords: criminal globalization, corruption, the informal sector, economic policy, economic security, economic interests

\section{Introduction}

In modern Russia during the years of market reforms shadow economic relations, manifested in the informal sector of the economy began to grow rapidly, reaching, according to experts, about $40 \%$ of the national economy. Shadow economy and shadow economy are the result of disease of the economy, changes in the system of economic relations society. The expansion of these relations are extremely harmful to the national economy of the country, has a negative impact on the moral and legal sphere of society, distorts the identity of many people, undermining state security, reduces the competitiveness of the national economy on the world 
market. Society and the state must actively influence the roots of generation of shadow economic relations, which, in all their diversity, have a common basis - deformation of the socio-economic system of society.

One of the major problems hindering positive economic growth, the criminalization of various parties of activity of economic entities. Economic environment where you have to work and develop Russian enterprises, is formed by the flow of legal and criminal capital. Efficient operation and development of Russian organizations is impossible without constant combat the shadow component of the Russian economy. The influence of the shadow economy in Russia is so great that the actual need for them to analyze and develop measures to reduce these effects.

Due to changes in the processes of functioning of the Russian society is changing and in the shadow economy. So, for organised crime in the economy is characterized by the following trends: "bipolarization", i.e. numerical growth few significant economic crimes and at the same time strengthening the negative qualitative characteristics (increase in the volume manipulated financial and material resources, the increasing sophistication of committed crimes and so on) major economic crimes; in the total mass of organised economic crime removed a small contingent of persons, on the share of which falls increasing proportion of the amounts criminal turnover of capital and obtained illicit income; dissemination of the new nature of the criminal operations of the illegal receipt of money and property they are illegal operations with legitimate money and property.

The most important specific features conducive to the spread of the shadow economy in Russia, can be attributed: particularly entrenched kind of illegality and even antizionist thinking of a certain part of the population; the practice of pseudocontrol, which is expressed in the desire externally to control all the economic life and internally indifferent to the effectiveness of actual control; quasiinternational majority of public information systems, the lack of real dedication on the part of government officials in obtaining accurate information, the inability or unwillingness of the critical analysis and practical use of the information; the inertia control activities of a significant number of law enforcement officers; specific unique diversity is expressed in the large number of ethnic cultural criminal clans, bound together by a single system of ethnic relations; the huge disparity in the most important economic aspects; political instability, threatening social stability, the violation of vertical responsibility in political, economic and legal institutions, etc.

The study shadow economy is the problem of conditionality behaviour of economic agents. Rules that structure the economic interaction are reflective (external) and ethical (moral). If the behavior of individuals on the basis of reflective norms can be described on the basis of the methodological principle of limited rationality described in theories Simon, Heiner and others, the behavior, adjustable ethical standards is a model of substantive rationality, based in particular on the moral choice, which is based on the system of beliefs and notions (Kaz, 2007).

The asymmetry of the principles of limited and substationally rationality, which postulate research approaches, known as individualism and holism, forces us to pay attention to an alternative approach, based on the principle of relativity. Relativism as a philosophical principle of interpretation sociohistorically subjects in their relation to each other and their environment emphasizes the primacy of communication entities over their substance properties, priority integrity, consistency reality on its separate parts, the development over conservation. Methodology of relativism, practical manifestation in which economic research is the theory of interest, allows to resolve the dilemma of "individualism - holism". Economic laws are not valid in themselves, but are manifested through the mechanism of their action and influence of the totality of the economic interests of individuals, corporations and society in General. Economic laws act as the motive force of social action people, performing this function indirectly, through their economic interests.

Overcoming the asymmetry of individualism and holism, relativism makes the cognitive point of view to identify sustainable relationships between individuals (or groups) in their dialectical integrity without absolutizing the autonomy of the subject (institutions, group interests) reality relatively subjective reality embodied in individuals and Vice versa.

The underdevelopment of many aspects of the regulation of the shadow economy at all levels, weak institutionalization of policy of economic security, which in the Russian social and political conditions rests on manual control, have necessitated the use of alternative methodological approach to the study of the problem of regulation of the shadow economy as a threat to economic security associated with the theory of economic interests (Yuriev, 1997). 


\section{Materials and Description of the Subject Area}

Theoretical and methodological bases of research was fundamental concepts and hypotheses presented in classical and modern works of foreign and Russian scientists.

The research is based on the documents of legislative and Executive authorities of the Russian Federation; statistical and analytical data of Federal state statistics service of the Russian Federation, reference books, analytical reports and reports on shadow economy and corruption in Russia.

The subject of research is the complex of organizational and economic solutions aimed at effective regulation of the manifestations of the shadow economy in the national economy of Russia.

The object of research is the shadow of the economic transaction and interests that lie in their basis.

The basis of any shadow economic transactions lies natural needs of individual and business entity on receiving profit. However, the illegal nature of this transaction gains in that case, if economic agents are excluded from formal rules (and institutions) and/or when they ignore regulating their interests effect of the state.

\section{Methods and Techniques}

The authors identified three theoretical-methodological approach to the problem of the shadow economy as the threat of economic security. The first approach to the study of the shadow economy is ethical. Postulated that the criminals are fundamentally different from the normal law-abiding citizens. They do not control their behavior and do not think about tomorrow. Their behavior is irrational. This approach is featured in the moral obligations that may have emotional, ideological, religious basis or legal culture.

Under the second approach - structural-functional is investigated opportunistic behavior of economic entities evading compliance with accepted standards and rules in order to obtain the greatest benefits. Focus reflexive norms and used the economic principle of "cost-benefit". Unlike reflective ethical norm captures rights and obligations. It claims as the outer base of the steps, in effect, forced or voluntary. Accordingly formed mutual expectations of economic agents interaction and motivation. In the framework of reflexive regulations distinguish between legal norms and conditional rules.

Based on structural-functional approach, the shadow economy is investigated within the existing institutional structure. However, out of sight remains a process of transformation of the socio-economic system. Therefore it is expedient to use the third approach to the study of the shadow economy in the context of the theory of economic interests.

\section{Results}

\subsection{The Main Vectors of Regulation Shadow Relations in the Russian Economy}

The decision regarding the selection of an economic operator institutional environment for legal or illegal business is determined based on the ratio of transaction costs, which arise on the basis of concluded deals. In other words, people oriented not only under the influence of the absolute imperative to the requirements of the law, but in connection with the potential benefits from such compliance. The motivation of a person to arbitrary enforcement of laws appear only when the state can contribute to the realization of the interests of the individual through the leveling of transaction costs in the legal sector of the economy.

Turning to the broader interpretation, we can say that the reasons for the existence of the shadow economy is directly connected with the problem of competition that exists within the boundaries of the market space. The shadow economy should be considered only as one of the forms of imperfect competition. The existence of such forms of imperfect competition violates both legal and moral-ethical norms.

Analysis of shadow economy in Russia have identified the following phases of its development:

The first wave (1991-1994). Liquidation of centralized state planning and organizational structures. Artificially supported by the government of the disparity of prices on the domestic and foreign markets, as measured by many orders, also led to widespread speculation. Commercial company purchased goods and resources on domestic prices, and sold them abroad over the world. Formally, this process did not violate existing laws, but actually getting super profits made possible because in these operations was invested a considerable part of funds of criminal capital. Increased the number of internally displaced people (informal businesses that rely on informal sources of earnings.

The second wave (1995-1996). This wave coincides with the second stage of privatization, which is associated with virtually shady deal of the state authorities with financial operators. Such objects of state property, as oil 
fields with the appropriate infrastructure, which is necessary for the processing and production of crude oil, were distributed during this period among a fairly limited circle of persons.

The third wave (1997-1999). This time to knit with an increasing growth of the shadow economy and economic crime. With substantial losses from this expansion has suffered small and medium business.

The fourth wave (after 1999). Happened a kind of "modernization" of crime, i.e. the transition to more clearly structural and hierarchically organized criminal activity, formed on the principle of corporate.

Of course, one cannot ignore the social and cultural peculiarities of the Russian mentality (contempt of law, private property, and so on) that have an impact on the functioning of the shadow economy. International studies show that the shadow economy is a universal phenomenon. She penetrated both West and East, both in developed and poor countries.

The most important factor criminalization of the economic system became the socio-economic policy. Its impact in this direction was expressed, first of all, the following line to the exception of the state's role as an active agent of economic life that involve the theories of the "free play of market forces". It was released field for shadow economic behavior: an introduction regulatory and economic mechanisms that create criminal situation; the gap in time between the adoption of normative acts regulating the rules of economic behavior, and creation of organizational-technical base for their execution. This situation, on the one hand, initially puts the entrepreneur to the status of the offender, which in turn makes him the object of extortion, on the other, creates a climate of impunity for violation of the established rules; sharp property stratification of the population with simultaneous loss of his considerable part of socially important landmarks, the substitution of their "ideals" of consumerism.

The most important features of the development of the shadow economy in Russia is connected with the state action: anti-social character of the market reforms in Russia; non-legal nature of economic transformation; the oligarchic nature of big business in post-Soviet Russia; extremely weak ethical basis of entrepreneurship.

Poverty leads to rapid development of the shadow economy. The shadow economy, in turn, plays poverty, resulting closes a vicious circle. Informal employment allows people to survive, but it does not solve the poverty problem, as they cannot receive any medical care, education, a full pension.

Poverty cannot be reduced to reduce the consumption of material goods. She is accompanied by a profound change in mentality and life practices. If the state of poverty continues long enough, it folds up and is reproduced sustainable social type and way of life of the poor, an integral feature of which is the shadow activity. As a result, in the medium unsettled society is formed shadow morality.

A considerable number of people, not finding a reliable social niches, losing moral values, comes to crime.

Unsettled young people is a source of recruitment for various security organizations. Such sources include and veterans of the Afghan war and the Chechen campaigns. Difficult life circumstances provoke shadow activity and refugees from the "hot spots".

Especially the crime is a social "floor". This category of people includes the most different social layers, from the homeless children and teenagers up to the homeless and the destitute. They are attractive for various types of criminal business.

World practice shows that the higher the living standard of the population, the less the share of the shadow component in the national economy.

The functions of the state should not be restricted only to ensure rights and freedoms of economic activity, private property. The state should recognize its responsibility for the welfare of their citizens and social compromise in society. In modern society, a social policy designed to perform two closely related basic functions - protection and development.

Thus, the modern welfare state assumes a much greater range of responsibilities. The main areas of implementation of social policy in relation to neutralize the shadow economy are the following: labor safety; protection of labour rights; social partnership; promotion of employment; assistance to the unemployed; the regulation of income; provision of pensions; social care; ecological safety; protection of social rights of citizens.

The modern Russian situation in accordance with the policy, aimed at strengthening of state institutions, which determines the possibility of stabilizing the economy, specifies the need for effective functioning of the state mechanism, creating favorable conditions for combating the shadow economy. 


\subsection{Theory and Practice of Realization of Economic Interests in the Informal Sector of the Russian Federation}

We can distinguish two main types of shadow economy - "criminal economy" and "emergency illegal economy." The process of implementation of economic interest in the criminal economic cycle is presented on figure 1.

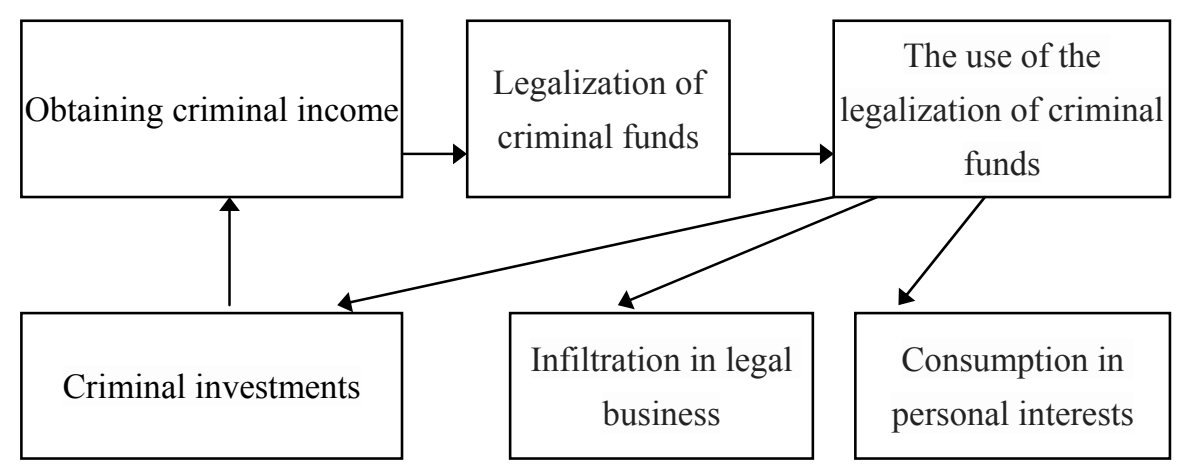

Figure 1. Criminal economic cycle and the implementation of economic interest

Russian business is mostly built on the combination of legal and shadow of transaction costs, which forms the predominance of the "grey" market. In most cases paying taxes combined with the cost of their size. Balancing on the verge of legal and illegal situation makes the business more agile. Accordingly, the process of legalization of business means that the situation of predpochtitel legal transaction costs. This does not mean that their cost must be reduced. The reverse movement, - increasing the value of the illegal transaction.

In the dialogue of commercial structures and the criminal world after 1999. we can identify the following transformation:

1. The criminal world is becoming more organized. The rules of relationship between crime, business and government acquires a stable character.

2. Is the interpenetration of crime and business. Entrepreneurship is becoming the main channel for the legalization of crime, while crime is an integral element of entrepreneurial activity.

3. The intensity of the dialogue of the criminal world and business is highly uneven across sectors. The least crime are non-scientific activities (marketing, consulting, and so on), which is explained by the low share resulting in these areas means.

4. The criminal world is becoming more functionally necessary element of business.

5. The criminal world is experiencing competition from actions of the public institutions and organizations.

The ratio of the impact of the shadow economy and development organizations and economic complex in many respects is determined by how skillfully controlled and impact on the economic interests of law enforcement bodies.

A special system of relations within the Russian regions, based on the maximum sovereignty and autonomy, makes them a kind of criminal enclaves. The mechanism of shadow economy as an organic component of the mechanism of functioning of the economies of these regions, they are beginning to affect the livelihood of these regions, as almost the entire volume of the resulting tools and resources controlled by the people, in one way or another connected with organized crime.

The specificity of domestic economy as a segment of the informal economy is in its internal autarky, exclusion from space transactions.

Chronological coincidence of interest to the household and studies of the informal sector is not accidental. Attention to the informal economy provoked the interest of the household as one of its segments, most clearly contradicts the logic of the "economic man". Home Economics was one of the semantic spreads problematic site of the informal economy. The relationship of domestic and informal economy can be traced, at least, on three grounds, based on which, in the thesis proposed a package of measures on regulation of activities of households.

1. "Self-sufficiency" of the household members is legal "production facilities" of the informal economy. Home Economics - nepratigais law and the most habitual way of informal world. However, "food independence" of the household is usually based on his "resource dependencies" from the formal economy, as the qualification 
potential and the resource endowment of the home economy is often traced back to its linkages with the formal sector. As a result, domestic work is not an isolated element, while the peripheral area of the complex compositions of social labor.

2. Household, following its own logic and morality survival, authorizes the degree and intensity of participation of its members in the informal economy, including the shadow economy and criminal. The care of the individual from under state control means its transition in the area of private control schemes, the most important element of which is the controlling family.

3. The household is the most loyal consumer of the products and services of the shadow sector. It is about the goods of daily demand.

Households open-ended fiscal norms pay for the products of shadow businesses, providing them unaccounted-for cash. The attractiveness of households as consumers forms of sectoral priorities of the shadow economy.

But in these conditions, households maintain their economic importance. They take on the function of the removal of contradiction between the mass production and standardized tools, on the one hand, and the individualized needs of the consumer, on the other.

\subsection{Criminal Globalization}

In the modern world, almost none of the countries do not develop in isolation from the others. The economy of any state becoming a part of the world economy. "Dissolution" of national economic systems in the world economy has led to a situation where the welfare of any state comes in dependence on the economic activities of citizens, and events that can occur on other end of a planet.

The processes of economic globalization has caused a number of new global challenges that affect all countries without exception. The resolution of such problems is possible only if the volume of the United efforts of the entire international community. We can say that the very existence of our civilization and its future development, directly conditioned with the solution of global problems.

Important social global problem is the problem of criminal globalization, increasingly threatening scale. When used this term, then it comes to that stronger on the world development impact of destructive forces that would violate legal norms and to level accepted in modern society and rules. The question of criminal globalization caused not so much by transnational organized crime, formed as international terrorist organizations, and how many functioning perfectly legal firms and functioning on a legal basis the governments applying the methods criminals and engaged in illegal activities on a global scale.

It should be noted that in the Russian literature comprehensive picture of the criminal global problems is only beginning to emerge. Specialists prefer to analyze them separately, resulting in a "behind the trees often not see the forest". Holistic research on criminal globalization in the Russian literature is not at all.

The world economy under the influence of the processes of criminal globalization actually forks. The first side includes legal processes and activities, and the second shadow and illegal. We can say that almost every legal element of the world economy has its illegal similar. For example, one of the participants of legal side of the world economy can be considered as transnational corporations and national governments, their "illegal twins" are international criminal groups (such as the Italian mafia, Chinese triads, the Colombian drug cartels and other), which origin national-tion, but are transnational in scope. Internationalization within the boundaries of legal economy leads to the creation of regional blocs (NAFTA in North America, the EU, in Western Europe), the illegal economy are formed groups like "Andean triangle" in Latin America or the Golden triangle in Southeast Asia, in which cooperation is implemented national criminal groups.

In accordance with the above, we can conclude that the result of the course of criminal globalization is the birth of a global criminal economy, considered as a system of interdependent transnational criminal activities.

When considering transnational criminal activities should highlight two specific block. Thus, there are important issues that are connected with the relations developed countries ("rich North") and developing countries (the"poor South"). At the same time, there are criminal, which relate only to developed countries.

Such a split of the world and in part led to the emergence and further development of international cases of criminal crafts. In this situation, firstly, such developed countries as the USA, Western Europe, Japan are so rich that people "Golden billion" were free to meet the most sophisticated needs of even the official morality. So, the demand for art objects for the rich snobs, drugs for hippies and artists for young children to childless families easily converge with the active offer from the underworld peripheral States. Secondly, the latter need in the 
performance of Western civilization (modern weapons, as well as the prestigious consumer goods), but on the other hand, they have no means to lawfully acquire it. The offer of these products already provide criminal organization developed countries. Finally, parallel to the official world market is created and illegal, that is, for the most part the structures of organized crime operating in countries of peripheral capitalism. Such illegal world market includes smuggling as prohibited goods (such as weapons and drugs) and so the legal turnover of goods (cigarettes, cars, diamonds), trade in counterfeit and illegal migration.

Economic development in the rich countries of the North are also produces criminal globalization, but slightly different. The most important criminal global problems arising in the relations between developed countries, is:

1) the smuggling of legal consumer goods;

2) money laundering and concealment of incomes;

3) computer crime;

4) economic espionage.

The increasing development in global scale of the informal economy can lead to a truly paradoxical effect. So, at first glance, the integration of the economies of individual countries in the processes of globalization in its essence should lead to efficiency control of the economy. This trend really is, but along with it applies diametrically opposite: a significant number of sectors of the economy (and even geographical areas) actually disappear from the field of state control. In parallel, they are still integrated into the world economy. Such integration has a stimulating effect on specialization in criminal markets.

Researchers "empires" of the drug trade in Latin America in the 1980s was developed the term "grey zones". This category was the analogy of the term in the dictionary of the pilots, who are so called those areas that were inaccessible, radar control. These researchers "grey zone" are a concept, structural and economic, not only geographically.

Today we can say that basically the entire international financial business sustainably "grey". This color is gradually acquiring and international Internet economy, which are the fruit of scientific and technical progress.

Many opponents of globalization believe that the so-called "new international order", in accordance with their position contains a threat of global totalitarianism. In our opinion, globalization carries as the beginnings of a "new international order"and the so-called "international disorder", existing in the form of criminal globalization.

\subsection{Opposition Shadow Relations as a Basis Mitigate Imbalances Economic Interests in the Russian Federation}

Since the economic and political spheres are closely intertwined, there is reason to believe that one cannot exist without the other, and the second is the continuation of the first.

If a few years ago, analysts spoke mainly about shadow phenomena in the economy, in recent years they have increasingly focused shadow of power and shadow law.

The main reasons and sources of formation of the shadow of political power researchers consider, first, latent deviant behavior of a considerable part of Russians; secondly, a shadow economy which, according to estimates, is $30-80 \%$ of Russian GDP and act as a cause and a consequence of shadow politics.

Dynamics of corruption crimes is presented in figure 2.

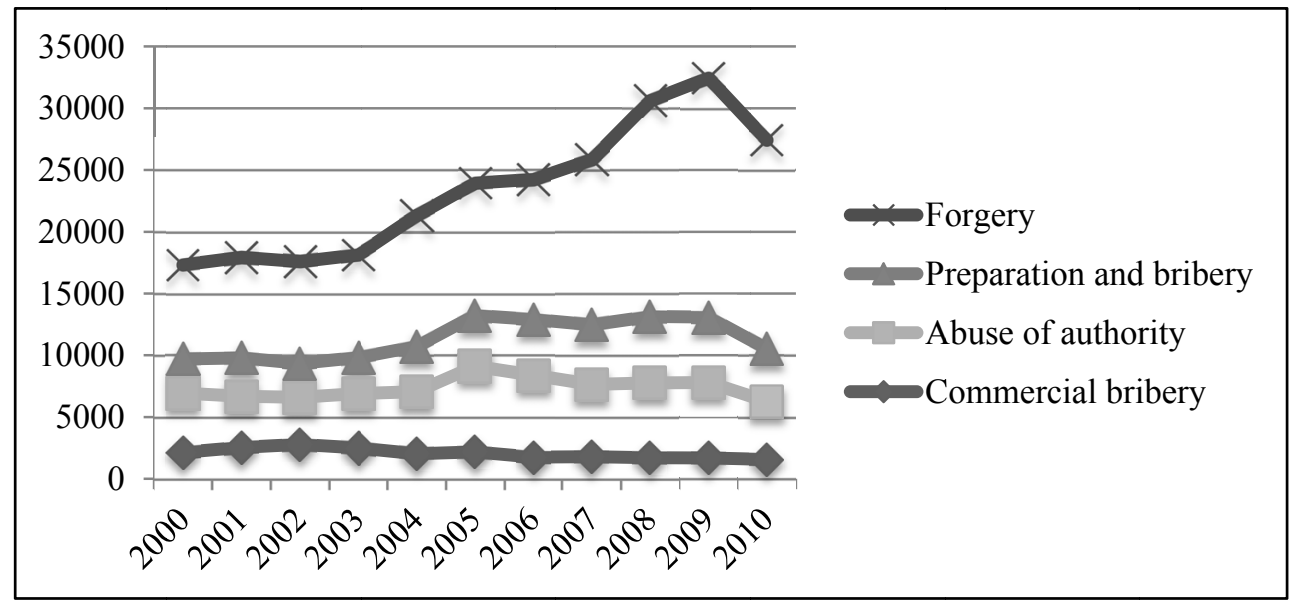

Figure 2. Dynamics of corruption crimes (Federal Treasury Department in the Vologda region, 2011) 
Corruption has penetrated almost all spheres of life of the Russian society. According to various estimates, to ensure special relations with representatives of the state apparatus commercial structures sent from 30 to $50 \%$ of its profits. Criminal groups are also directed to the bribery of officials of a significant amount. But you can highlight and so-called domestic corruption. This includes bribes from ordinary citizens in the process of obtaining medical, educational, housing and the communal-national, and similar services.

Only a strong state can effectively impact on the shadow economy. For so the state was "strong"and not "force" and its role in the shadow economy has been minimized, the following important aspects: the national idea that unites citizens around the basic moral values of Russian civilization (state, social justice, spirituality and so on), rejecting the cult of money as "ruler of souls"; the authority of political power, is possible if the authorities, expressing the interests of the people, will be competent, efficient, non-corrupt; the state's ability to create a healthy competitive environment in the national economy, which would be set barriers for shadow activities of the mafia and oligarchic structures.

The implementation of measures for combating the shadow economy requires balancing the interests of the state and other subjects of market economy.

It is advisable to pursue a policy of legalization constructive part of the shadow economy in three main directions:

1) bringing the regulatory framework in such a condition, when the role of officials in dealing with economic issues is reduced to function of the state representatives. Such a policy will lead to the eradication of "institutional traps", the desire to minimize the required payments to the state, corruption perception as an inevitable phenomenon.

2) increasing the efficiency of the officials ' work, creation of effective mechanisms of control over their activities, the introduction of compensation from their tyranny.

3) the Fight against corruption, especially in the Executive authorities and courts.

It seems appropriate in the activities on improvement of information support of activity of management bodies of all levels to narrow the "shadow space" to provide for:

- acceleration of development of the whole Arsenal of methods for measuring non-observed economy, proposed international standards;

- improvement of processing programs standard data sets and special surveys, giving the opportunity to clarify the scale, geography and specifics of individual aspects of economic and non-economic shadow activity;

- further development of macroeconomic calculations by the stages of reproduction of economy and sectors using the institutional and functional approaches.

In our opinion, the main focus in this system measures should be the following solutions and events:

- conducting a General Amnesty for tax and economic crimes in the corporate sphere to a certain amount (for example, up to $1 \mathrm{mln}$.);

- reimbursement of losses the population from inflation and "privatization" of shares of state-owned banks and enterprises;

- introduction of a system of economic incentives output legal entities and citizens of the shadow sector of economy;

- establishing economically viable, equitable, but clearly administered taxation;

- promote non-cash payments and control of cash turnover (particularly in foreign currency);

- carrying out of clear and consistent state policy of support for private legal enterprises;

- introduction of the state system of measures for the effective protection of the owner and the lender;

- conducting real administrative reform (the state apparatus should stimulate the development of private legal business and Economics);

- formation of incorruptible, fair and highly professional law-enforcement and judicial system;

- elimination of organized crime in all spheres of society, particularly in the informal sector of the economy and the financial system.

The success of the fight against the shadow economy is possible only under condition of its mass support by society, and this, in turn, is achievable at a high level of citizens ' trust towards state institutions of power and administration. 
The shadow economy to eradicate completely impossible, but it is possible to reduce it to acceptable and not so great for the economy level. Then a reasonable option in the strategy of reducing the influence of the shadow economy should become its specific weight not exceeding $10 \%$ of gross domestic product. This state can be achieved by a sharp reduction of shadow operations oligarchic structures, corruption and bribery in the state apparatus. It is necessary to take steps for the legalization of a significant part of the forced nelegalnoj economy.

When selecting the mechanisms for implementation of the strategic objectives it is important to find an optimal balance between economic and administrative measures of state influence on shadow economy.

The main directions of the fight against the shadow economy in Russia is presented in figure 3.

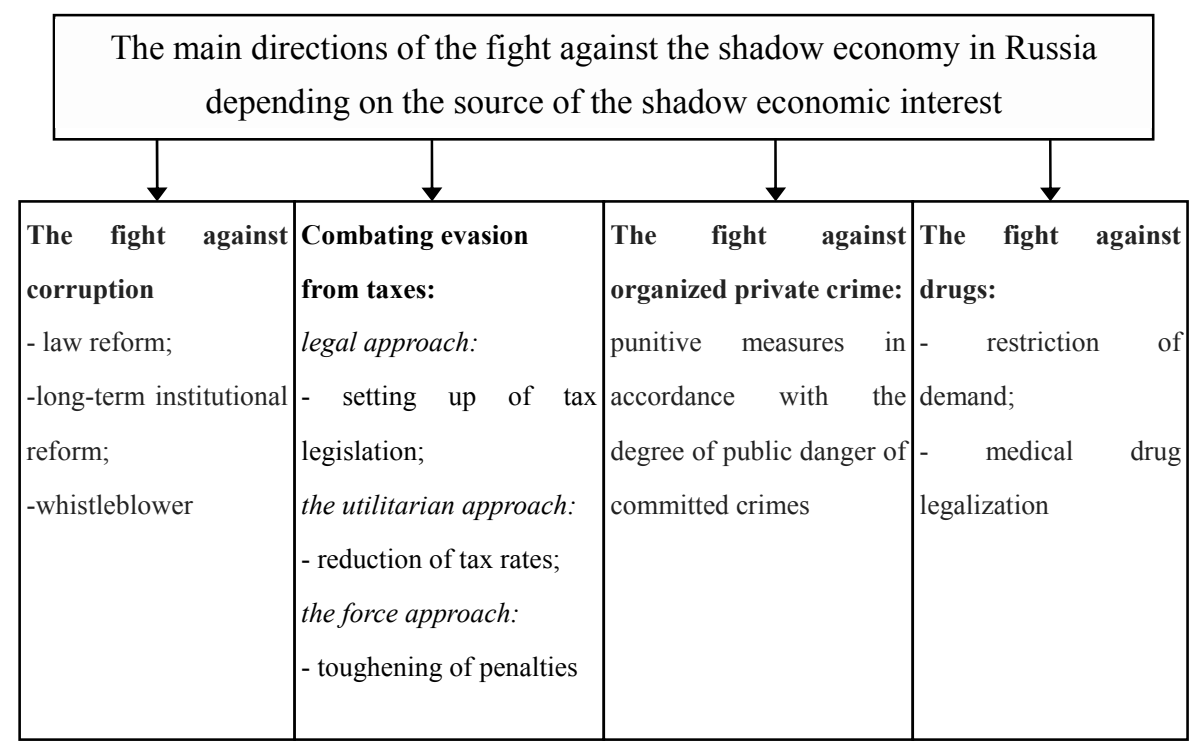

Figure 3. Measures to combat the shadow economy in Russia

The study proposed the following action programme for the state: it is necessary to stimulate the non-cash turnover; to prevent the uncontrolled availability and attraction of loans, disposal of property and assumption of liabilities of the insolvent enterprises and citizens in particularly large amount, as usual lending to the population today - the process is very difficult, especially for rural areas; it is important to decentralize, to strengthen the judicial and law enforcement bodies, securing the relevant institutions part of tax revenues; you must make protection of the rights of shareholders, investors and lenders in the state priority.

The state should not only be aware of the significance of the problem of the shadow economy, but also to have the political will to be able to take decisive actions on the improvement of market relations.

The state bears full responsibility for the scale of forced nelegalnoj economy. It should seek to minimize this phenomenon is the result of sound economic and social policies. Moreover, it should be noted that indirect measures (improvement of tax and labor legislation, social protection, training and retraining, etc.,) are more effective than direct administrative measures.

\section{Discussion}

Significant growth of interest in the shadow economy is observed from the end of the 60 's - early 70 -ies of the last century.

With regard to forced nelegalnoj economy, that, in General, the findings of this study do not protivorechat position, formulated Asato, according to which this type of shadow activity is a response to economic entities at the gap in the economic mechanism, ignoring their needs and requirements (Soto, 1989).

It should be acknowledged some positive aspects of such varieties shadow economy. These include, first, its stabilizing role: the large size of the shadow economy in developing countries can smooth out downs of production and the crisis on the world markets. The existence nelegalno sector also helps to realize their entrepreneurial potential, which remains unclaimed due to high cost of access to the formal market (Nikolaev, 1998). 
The policy issue is the scale of the shadow economy and its specific manifestations. If the shadow economy takes exaggerated the scale, this means that the state is not able to effectively regulate the economy and to create normal conditions for the functioning of entrepreneurship.

It is proved that the incidence of crime (including economic) directly related to the change in welfare of the population (Barsukova, 2004). When Hyper-scale informal sector should put the question is not about anti-social activities of economic entities, and about anti-social economic policy of the state.

The heyday of the shadow economy in modern Russia explains quite often, the fact that its roots go deep in the Soviet period that, as the shadow economy was formed by the economic Institute of Soviet society, she could not suddenly disappear even under the most favorable conditions. This is so, but hardly the only this can explain gipertrofirovannyj shadow economy. In addition, this approach ("blame the Soviet regime and the Communists") largely contains the ideological component.

There are those who refers to the Russian mentality and is the shadow economy (especially embezzlement and bribery) as an integral part of the Russian civilization.

In our opinion, the specificity and scale of shadow activity in modern Russia is primarily due to the loss of the state in the 1990's ability to manage socio-economic development of the country and violation of balance of interests between economic agents.

\section{Conclusion}

The study found that shadow the potential of the Russian society because of its high social structure, including: a large proportion of the population classified as poor; a significant share of the unemployed and fictitiously employed; the availability of social "bottom"; a significant proportion of refugees from the "hot spots"; a large number of unsettled demobilized persons in the state of post-war shock". On this basis, defined major directions of social-economic policy to neutralize the effects of the shadow economic activity. Shadow the potential of the Russian society is a consequence of the anti-social nature of the state policy.

Organizational-economic development of the shadow economy as a subsystem of the economy is the implementation of the various forms of coordination of interests of business entities engaged in their business completely or partially criminal way. This consolidation in addition to criminal advantages, gives exclusive competitive advantages in legal business, including possible: to establish and maintain prices (tariffs), discounts in everyday business at the regional, sectoral or another level; to increase, decrease or maintain prices at auctions and tenders; to divide the market by territorial, sectoral or other means; to restrict access on a territorial or sectoral market or eliminating from it other economic entities.

Organizational-economic mechanisms of anti-spam shadow may be necessary to design, from the perspective of the theory of economic interests, based on the correction of imbalances interests of economic agents based on the priority of economic security.

The study determined the main directions of state influence on shadow economy:

1. The state strategy of social-economic development of the country: minimization of the shadow economy; formation of the basic macroeconomic parameters of the national economy on the basis of fair competition; effective Antimonopoly regulation; fixing of maximum permissible size of the shadow economy.

2. Economic legislation: an acceptable level of taxes and customs duties; transparency of financial activities of economic entities; simplified forms of registration and reporting; the responsibility of banks to depositors.

3. Social policy: formation of a social state; establish decent living wage; prevention of deep social differentiation of the society; minimization of shadow operations in the system of labour relations; special attention to the problem of youth employment.

4. Relations with the business: equidistance business and government; state support of small and medium business.

5. Punitive function: traditional crime; the corrupt part of officials; shadow operations oligarchic structures.

6. The educational function: the creation of a culture of abiding law; the condemnation of the cult of violence, permissiveness, drug trafficking, prostitution, pornography and so on; the formation of the national idea based on the moral principles of the society.

7. Cooperation with civil society institutions: coordination of activity of local governments and law enforcement agencies; use of materials of independent investigations in the field of economic crime, conducted by the media; cooperation in the framework of the system of social partnership with organizations of entrepreneurs and trade 
unions on issues of social policy, entrepreneurial corporate ethics; cooperation with public and religious organizations in the sphere of spiritual education of the society; cooperation with public chambers.

8. Cooperation with international organizations: development of General principles of combating money laundering, corruption, fraud; the exchange of operational information on economic crime, joint investigation; exchange of experience in the international conferences, seminars, exercises; taking into account the opinion of the authoritative international organizations about the state of the shadow economy.

The state impact on the shadow economy should be differentiated. Forced illegal economy should be mainly indirect impact (through the creation of favourable market environment), and the criminal - mainly the impact of direct administrative methods on the basis of constitutional law, with the active involvement of law enforcement bodies.

\section{Acknowledgments}

This article was prepared in the framework of scientific-research works Tambov state University. YOB Derzhavin for the Ministry of education and science of the Russian Federation "the Study of the theoretical foundations of sustainability developed socio-economic systems" (registration number: 6.5727.2011) and "Theoretical and methodological development of the political-economic concept of "Statehood" as the basis for Russia's modernization" (registration number: 6.1376.2011).

\section{References}

Barsukova, S. Y. (2004). The informal economy: An economic and sociological analysis. Publishing house of the SU-HSE, Moscow.

De Soto, H. (1989). The Other Path: The Invisible Revolution in the Third World. Harpercollins.

Federal Treasury Department. (2011). Report on economic education in the Federal Treasury Department, Vologda oblast on the theme "Corruption as a form of illegal activity. The status, structure, dynamics and tendencies of crimes of corruption". Retrieved July 22, 2014, from http://webcache.googleusercontent.com/ search?q=cache:DS-71UHEVnQJ:vologodskaya.roskazna.ru/file/separate_fs/80.146004.ekonomuceba.DO $\mathrm{C}+\& \mathrm{~cd}=1 \& \mathrm{hl}=\mathrm{en} \& \mathrm{ct}=\mathrm{clnk} \& \mathrm{gl}=\mathrm{ru}$

Kaz, M. (2007). Lacunas in the structure of economic knowledge and non-classical rationality. Economic issues. 6, 45-62.

Nikolaev, I. Ana economy: Causes, consequences and prospects. Society and economy, 6, 31-49.

Yuriev, V. M. (1997). Tranzithornoe economy of Russia: the determinism of economic interests. Finance and statistics, Moscow.

\section{Copyrights}

Copyright for this article is retained by the author(s), with first publication rights granted to the journal.

This is an open-access article distributed under the terms and conditions of the Creative Commons Attribution license (http://creativecommons.org/licenses/by/3.0/). 